\title{
IMPACT OF EXPERIMENTAL TEACHING METHOD "LANGUAGE THROUGH SPORT" ON MOTIVATIONAL STRATEGIES OF WEIGHTLIFTING SPECIALISTS
}

\author{
E. Mileva*, V. Slavova, N. Yankova, V. Panayotov \\ National Sports Academy “Vassil Levski”, Sofia, Bulgaria
}

\begin{abstract}
Recently, there have been outlined some problems in the motivated participation of students in the educational process. These ones presuppose the optimization of traditional teaching methods and the application of new methods, techniques and approaches in the learning process. The necessity of introducing a new-invented educational model for students' training at NSA "Vasil Levski", combining the foreign language teaching and their sports training is imposed by the need to improve the existing educational practice both in sport practice and in foreign language learning. The new-invented teaching method "Language through sport" for weightlifting and power lifting specialists has not been developed so far in this specific educational context. The experimental teaching method has been elaborated and applied by simultaneous implementation of foreign language learning of standardized international terms in the field of weightlifting and power lifting in students' training sessions. The study of the impact of new-invented method "Language through Sport" on students' motivation is a reliable indicator of the efficacy of this training and teaching method in sports pedagogical practice, not only in weightlifting and power lifting but also in other sports disciplines.
\end{abstract}

Key words: foreign language, sport, experimental teaching method, motivation, students

\section{INTRODUCTION}

The issue of learning motivation is important and central in terms of increasing the quality of criteria of higher education and accrediting the individual professional fields and programs. The formation of an active attitude of students for learning is becoming a key indicator of quality education. This is a prerequisite for successful realization and provision of highly qualified professionals on the labor market.

Last few years there have been outlined disturbing trends in the motivated participation of students in the educational process. Teacher's responsibility is increasing in order to create new methodologies and approaches for meaningful and motivated inclusion of students in learning (1). The change of the educational paradigm is required - from produced and reproduced knowledge to a

Correspondence to: Prof. Eleonora Mileva, DSc, PhD, National Sports Academy "Vassil Levski", Sofia, Bulgaria; email: emileva2002@yahoo.com meaningful and applicable one in the context of constantly changing social environment (23-8).

Foreign language knowledge is a key competency whose development is important both for personal and professional realization of future sports professionals (3-4-8). Integrating foreign language teaching into sports training educational process is one of the most important tasks that higher sportspedagogical education have to realize.

The necessity of implementation of a modern didactic model for students of the National Sports Academy "Vassil Levski" combining foreign language education and sport training is predefined by the need to improve the existing educational practice both in sport and in foreign language. This new model, which is an innovation in training methodology, would help acquiring lasting knowledge and skills for practicing a foreign language. 
The methodology of foreign language teaching has evolved considerably nowadays (9). Modern programs focus on interactive teaching methods and integration of new technologies (3-4). The "Language through Sport" method designed for specialists of section "Heavy athletics" at the National Sports Academy "Vassil Levski " has not been developed so far in this specific educational context. The National Sports Academy as a higher education institution that provides training in physical education and sport has the mission of giving profiled knowledge to students by connecting the foreign language teaching with specific sport training in the academic program (5). In this regard, specialized foreign language teaching should seek to simulate authentic language environment and professional situations. This particular educational context has become even more important related to increasingly massive acquiring of basic English knowledge by students, mainly due to the widespread implementation of electronic channels of communication.

Some studies with close issues have shown the luck of similar learning experiences, so we focused on this unexplored approach to foreign language teaching "Learning by doing" in sports pedagogical practice. We believe that the individual interactive approach to implementing foreign language teaching combined with sport training is crucial to the efficiency of these classes. The classes conducted in real training conditions might have contributed to the application of the acquired knowledge in practice in the professional life of the sports pedagogic specialists.

In this connection, the experimental training has allowed the study of the effect of the combination of training sessions with the acquiring and improvement of standardized international terms in the field of heavy athletics. The study of the effectiveness of the applied "Language through Sport" method by taking into account changes in student motivation is a reliable indicator of the applicability of this training methodology in sports pedagogical practice, in both heavy athletics and other sports disciplines.

The aim of the present study has been to establish the effect of the applied training methodology by analyzing changes in learning motivation for weightlifting students of the National Sports Academy "Vassil Levski".

\section{METHODOLOGY}

An experimental curriculum for language learning has been developed, as well as a specialized methodology for technical preparation adapted to the language training program including English terms used for describing different components of competitive exercises for weightlifting and power lifting. Ten training modules have been developed and implemented during training sessions, including thematic units in English, which have been foreseen. For this purpose, students have been divided in two groups: an experimental group $(\mathrm{n}=40)$ and a control group $(\mathrm{n}=38)$.

The language skills of participants in the finding experiment have been determined by applying complex assessment (written tests and oral testing) at the beginning and end of the experiment.

The training has been conducted in two stages according to a timetable for the implementation of the experimental curriculum. The developed evaluation system including tests for current language level of students on the topics studied has been applied monthly in order to assess the theoreticalapplied knowledge. The performances of the participants on the learning material included in both the experimental methodology and the traditional methodology have been examined.

At the beginning and at the end of the training, studies have been conducted on the level of learning achievements as well as on students' attitudes to experimental methodology, on their learning motivation in the context of the researched type of teaching. For this purpose, a questionnaire on motivational strategies (Motivated Strategies for Learning Questionnaire) (6-7) adapted to Bulgarian conditions (8), has been used at the beginning and at the end of the experiment. Test questionnaires in English have been added to the test batteries on motivational strategies in order to assess the satisfaction of the participants in the training.

During the first stage of the experimental training (summer term of academic 2017/2018 year) the experimental group' students have been trained on the newly developed complex methodology both in the technique of the competitive exercises in power lifting and the weightlifting (in Bulgarian language), as well as of the respective sports terminology in 
English. The control group' students passed practical training on the traditional weightlifting methodology and power lifting in Bulgarian.

A specialized mathematical and statistical data processing software SPSS 19.0. has been used as well as the Excel software included in the MS Office package. Variation and comparison analysis have been applied.

Motivational strategies have a strong impact on learning outcomes, and in some cases might have been a more serious and important factor in determining the efficiency of training methodology (10). The Motivated Strategies for Learning Questionnaire (6-7), applied at the beginning and end of the experimental training of the experimental group students $(n=40)$ contains two parts and consists of 81 statements divided into two categories: motivation (31 statements) and learning strategies (50 statements). Students from the experimental group have been given the first part of the test that relates to learning motivation. Students have been self-assessed on a 7-degree Likert scale, from 1 (not at all about me) to 7 (completely relevant to me). The test has been adapted to a specific educational context (8).
The initial study was conducted with the students from the Faculty of Sport, section "Heavy athletics", during the summer term of the 2017/2018 academic year, and the final study was conducted during the winter term of the academic year 2018/2019. The study has been conducted with 78 students aged 24 years and 3 months with an average sport experience of 7 years and 6 months.

\section{ANALYSIS OF RESULTS}

The application of the test at the beginning and at the end of the experimental training made possible highlighting the changes in the individual factors for student motivation by comparing the results of the two studies. The analysis of the results obtained in the initial study has revealed that "Task Value" ( $\mathrm{M}=$ 4.20), followed by "Self-Efficacy for Learning \& Performance" $(\mathrm{M}=3.63)$ and "Intrinsic Goal Orientation" ( $\mathrm{M}=3.61)$. "Extrinsic Goal Orientation" ( $\mathrm{M}=3.47)$ was assessed by students equally as for the factor "Control of Learning Beliefs" $(\mathrm{M}=3.47)$. The lowest value of the motivation scales is "Test Anxiety" $(\mathrm{M}=2.58)$ (Table 1).

Table 1. Distribution of factors in the initial study

\begin{tabular}{||l||c||c||c||}
\hline \multicolumn{1}{|c||}{ Initial study } & $\mathbf{N}$ & Mean & Std. Deviation \\
\hline \hline 1. Intrinsic motivation & 40 & 3.61 & 0.938 \\
\hline \hline 2. Extrinsic motivation & 40 & 3.47 & 1.001 \\
\hline \hline 3. Task Value & 40 & 4.20 & 1.247 \\
\hline \hline 4. Control of Learning Beliefs & 40 & 3.47 & 1.157 \\
\hline $\begin{array}{l}\text { 5. Self-Efficacy for Learning \& } \\
\text { Performance }\end{array}$ & 40 & 3.63 & 1.269 \\
\hline \hline 6. Test anxiety & 40 & 2.58 & 1.226 \\
\hline
\end{tabular}

The analysis of the results obtained in the final study reveals that for the study group $(n=40)$ the most serious changes in the mean values are established for the factors "Task Value" $(\mathrm{M}=$ 6.05), "Self-Efficacy for Learning" $(\mathrm{M}=5.67)$ and "Intrinsic Goal Orientation" $(\mathrm{M}=5.63)$, followed by "Extrinsic Goal Orientation"( $\mathrm{M}=$ 5.45). It is noteworthy that the factors "Control of Learning Beliefs" and "Extrinsic Goal Orientation" have similar mean values $(\mathrm{M}=5.55$ and $\mathrm{M}=5.45$ ), the lowest average being the Test Anxiety Factor $(\mathrm{M}=2.90)$ (Table 2).

Table 2. Distribution of factors in the final study

\begin{tabular}{||l||c||c||c||}
\hline \multicolumn{1}{|c||}{ Final study } & $\mathbf{N}$ & Mean & Std. Deviation \\
\hline \hline 1. Intrinsic Goal Orientation & 40 & 5.63 & 1.584 \\
\hline \hline 2. Extrinsic Goal Orientation & 40 & 5.45 & 1.729 \\
\hline \hline 3. Task Value & 40 & 6.05 & 1.562 \\
\hline \hline 4. Control of Learning Beliefs & 40 & 5.55 & 1.694 \\
\hline $\begin{array}{l}\text { 5. Self-Efficacy for Learning \& } \\
\text { Performance }\end{array}$ & 40 & 5.67 & 2.038 \\
\hline \hline 6. Test anxiety & 40 & 2.90 & 2.148 \\
\hline
\end{tabular}


The analysis of the collected data have shown that the use of the experimental teaching method "Language through Sport", based on innovative approaches organized in an active learning environment presented through attractive practical training activities, leads to higher values of the factor "Task Value" in the studied group. "Self-Efficacy for Learning \& Performance" along with "Intrinsic Goal Orientation" are identified as factors that have a significant impact on learners and include: interest in the learning content studied, learning to use the learning material, desire for realization, self-confidence and self-esteem, etc. The data has shown that "Extrinsic Goal Orientation" and "Control of Learning Beliefs" have similar means and are in balance. This confirms the fact that developing a constructive and supportive learning environment that involves the setting of daily and achievable goals is important for the effectiveness of the studied teaching methodology.

Comparison of mean values of the investigated factors in the initial and the final study reveals relatively large differences (Figure 1).

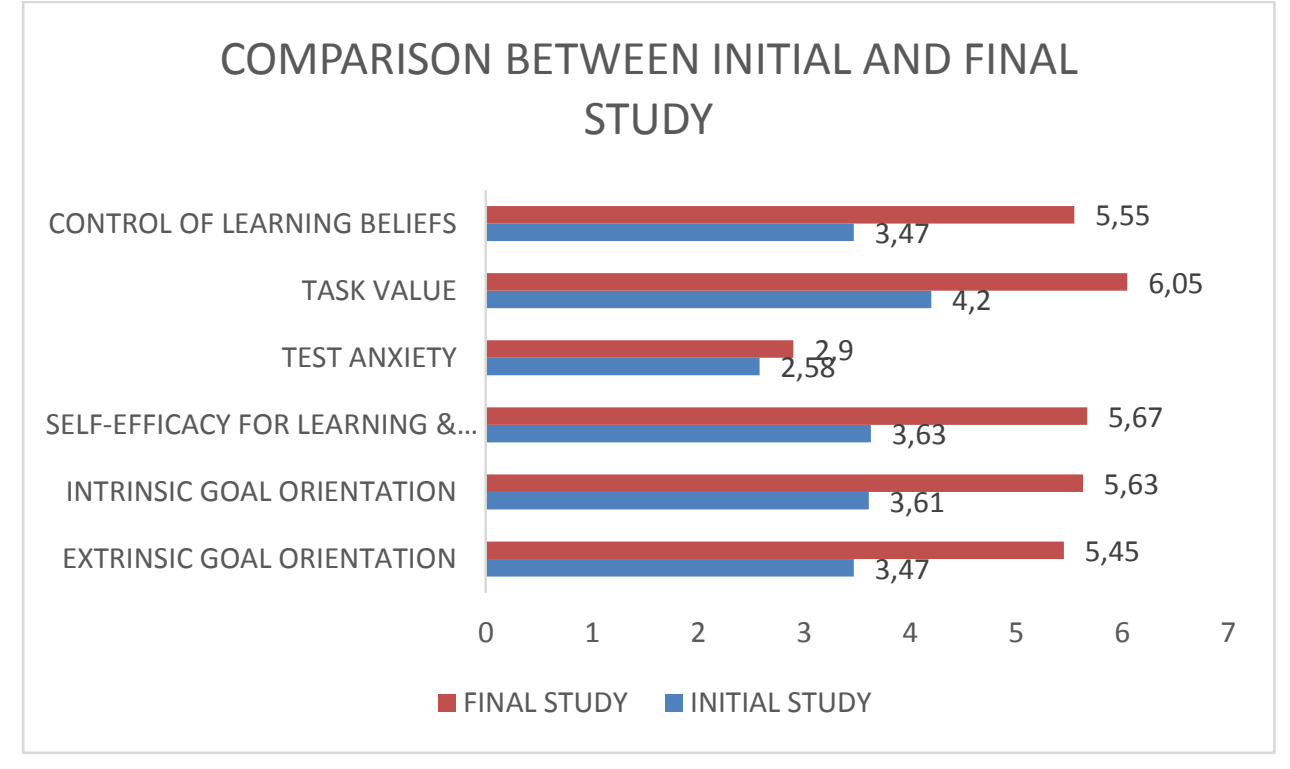

Figure 1. Comparison between initial and final study of students 'performances in experimental group

There is an increase in the means of the six distinct factors. It should be stressed that the greatest difference between the two studies have been for the first, second and third factors - Intrinsic Goal Orientation (initial study $M=$ 3.61, final study $M=5.63$ ), Extrinsic Goal Orientation (initial study $\mathrm{M}=3.47$, final study $\mathrm{M}=5.45$ ) and the Task Value (initial study $\mathrm{M}$ $=4.20$, final study $M=6.05$ ). This is probably related to students' perceptions about the importance of foreign language learning for personal and professional purposes.

The main argument for the established differences is the existence of serious internal motives related to the desire of students to master the specialized terminology in their sport, which would help them to be successful in the labor market not only in Bulgaria but also internationally. On the other hand, the impact of the innovative learning environment created during the experimental training as an external factor has a positive effect on the students learning motivation. The same difference is detected when comparing the results of the two studies on the factor "SelfEfficacy for Learning \& Performance" as in the initial study $M=3.63$, and in the final study $\mathrm{M}=5.67$. Consequently, the confidence of students in their ability to study and pass an examination is rather high, which is due to specific personal characteristics (selfconfidence is an important component in the personal dimension of motivation) and their assessment of the practical learning environment and the proposed thematic content.

The same significant difference is observed when comparing the means of "Control of Learning Beliefs" factor, for the initial study M $=3.47$ and for the final $-\mathrm{M}=5.55$. A minimal difference in the mean values of the "Test Anxiety" factor is distinguished, for the initial study $\mathrm{M}=2.58$ and for the final $-\mathrm{M}=2.90$. This is probably due to the numerous testings 
before, during, and after the experimental training.

It can be summarized that high levels of interest and assessment of the experimental course of foreign language teaching in training conditions have been established. The research of motivational learning strategies is important both for the good planning of the learning process and for evaluating the effectiveness of a training course and a newly implemented method of teaching. Students' interests are determined not only by internal, personal factors, but also by external factors such as teaching, interaction in the learning process. In this sense, the knowledge of motivational strategies that influence students, their changes from course to course and the design of an appropriate learning environment increases the willingness to learn and is an important pedagogical problem that has a positive impact on the learning outcomes.

\section{CONCLUSIONS}

Based on the analysis of the results on the impact of the experimental methodology "Language through sport" on the motivational strategies of weightlifting and power lifting specialists, the following summaries can be made:

- The experimental methodology "Language through Sport" has a positive impact on the interests and assessment of the students for the experimental training. Positive changes were observed for all factors studied between initial and final study.

- "Intrinsic Goal Orientation", "Extrinsic Goal Orientation" and "Task Value" factors stand out with the highest values.

\section{REFERENCES}

1. Dimitrova, N., Mutafova-Zaberska, J. Stimulating the intellectual activity in the education of children - judokas. In: Personality, Motivation, Sport; Vol. 10, NSA PRESS; Sofia, pp. 145-147, 2005.

2. Dimitrova, N. The factor motivation for judo training with children. International Journal of Kinesiology and Other Related Sciences. Research in Kinesiology, 2, 45: 161-163, 2017.

3. Hristakieva, T. Interactive techniques in teaching of sports terminology in English. Sport \& Science, 4: 132-141, 2017.

4. Hristakieva, T. Interactive Foreign Language Learning and Group Work. Sport \& Science, 1/2: 141-147, 2019.

5. Mileva, E., Yankova, N., Panayotov, V., Slavova, V. Study of attitudes of weightlifting students to teaching method "Language through sport". Ruse: Univesity of Ruse "Angel Kanchev", Proceedings, Vol. 57, book 6.2, pp. 75-80, 2018.

6. Pintrich, P. R., Smith, D. A. F., Garcia, T., McKeachie, W. J. A manual for the use of the Motivated Strategies for Learning Questionnaire (MSLQ). Ann Arbor, MI, USA, 1991.

7. Pintrich, P. R., Smith, D. A. F., Garcia, T., McKeachie, W. J. Reliability and predictive validity of the Motivated Strategies for Learning Questionnaire (MSLQ). Educational and Psychological Measurement, 3, 53: 801-813, 1993.

8. Slavova, V., Mileva, E. Study of sports students' motivation for foreign language learning. Ruse: Univesity of Ruse "Angel Kanchev", Proceedings, Vol. 52, book 8.2, pp. 63-67, 2013.

9. Stefanova, P. Foreign language education learning, teaching, evaluation, Siela, Sofia, Bulgaria, 2007.

10. Yankulova, J. Pedagogical psychology, Paradigma, Sofia, Bulgaria, 2012. 